\title{
¿Rehacer el Demos? Entrevista con Wendy Brown*
}

\author{
Sebastian Raza, Samuel Burgum y Jorge Daniel Vásquez**
}

\section{INTRODUCCIÓN}

El presente diálogo con la filósofa y politóloga Wendy Brown, tiene como finalidad contrastar sus indispensables y estimulantes ideas con los acontecimientos y problemáticas políticas recientes, enfocándose particularmente en su libro El Pueblo sin Atributos (2016) y refiriéndose brevemente a La Política fuera de la Historia (2014 [2001]) en el contexto actual. Las preguntas fueron formuladas de manera colectiva y la entrevista fue llevada a cabo vía Skype por Sebastián Raza el 23 de Mayo del 2017. Agradecemos a Wendy Brown por la generosa contribución de su tiempo y por responder a nuestras preguntas de forma directa y clara. Esta entrevista ha sido también publicada en inglés por Theory, Culture E Society.

\footnotetext{
* Prof. Wendy Brown (UC Berkeley - USA) ha recibido múltiples reconocimientos por su labor intelectual orientada a interrogar críticamente las estructuras de poder, las identidades políticas, ciudadanía y la subjetividad política en las democracias liberales contemporáneas. Sus obras han sido traducidas a más de 24 idiomas. Actualmente, Wendy Brown es profesora en el departamento de Ciencia Política en UC Berkeley. Su último libro 'Undoing the Demos: Neoliberalism's Stealth Revolution' (2015) (traducido al español como 'El pueblo sin atributos: la secreta revolución del neoliberalismo' (2016)) se ha convertido en una referencia ineludible para entender el panorama político contemporáneo.

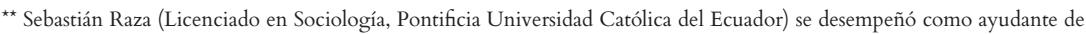
cátedra bajo la supervisión de Emilio Cerezo desde 2012 hasta 2016. Actualmente cursa estudios de Maestría en Sociología en la Universidad de Warwick, Reino Unido.

$凶$ : s.raza-mejia@warwick.ac.uk

Ph. D. Samuel Burgum (University of Warwick). Investigador y teórico de las relaciones de poder y resistencia de movimientos políticos contemporáneos. Ha dedicado buena parte de su trabajo al estudio del movimiento social Occupy Wall Street.

\: s.j.burgum@warwick.ac.uk

Jorge Daniel Vasquez (University of Massachusetts-Amherst). Ensayista, investigador y catedrático. Ha realizado estudios en Educación, Filosofía y Sociología en universidades de Porto Alegre, San José de Costa Rica y Quito. Docente de la Pontificia Universidad Católica del Ecuador

$凶$ : jdanielvasz@gmail.com

${ }^{\star \star \star}$ Traducido a español por Erika Rosado. Revisado por Sebastián Raza.
} 
Pregunta 1: En El pueblo sin atributos (2016), usted aborda la imposibilidad de acciones políticas radicales o emancipatorias mientras el mercado sea la única fuente de ‘veridicción' y su ficción - el Homo Oeconomicus - el último hombre en pie. Para comprender esta problemática, usted ha desarrollado una interesante relación triangular entre Foucault, Marx y la Democracia, que ha resultado ser útil, pero, a su vez, cuenta con detractores en cada punto. ¿Podría profundizar un poco más respecto a este espacio teórico que ha creado? ¿Por qué es importante y de qué manera se pueden abordar las críticas que surgen en cada punto?

Brown: De Marx aprendemos a pensar en la economía política y, de manera más específica, en el capitalismo como elemento fundamental en la configuración de la existencia humana contemporánea. Por supuesto se debió actualizar a Marx para lograr captar primero el capitalismo Keynesiano; después, el más reciente capitalismo neoliberal; y, ahora, el capitalismo financiero. Pero de Marx aprendemos a pensar en el mundo en términos de la organización de las formas de producción y de lo que algunos llaman 'el modo de predicción' (es decir, el capital financiero). Aprendemos a pensar en la economía política en el sentido más amplio y profundo como la localización del poder, la dominación y la explotación, así como de los puntos de resistencia.

De Foucault aprendemos a pensar el modo en que somos gobernados por regímenes de verdad (orders of reason), y por lo que él más tarde denominó como formas de 'racionalidad de gobierno' o 'razón gubernamental'. A diferencia de Marx, estos regímenes de verdad (orders of reason) no pueden ser reducidas a los modos de producción o a la economía política. Por el contrario, éstas son racionalidades normativas a través de las cuales somos producidos como sujetos, que permiten y legitiman el surgimiento de técnicas a través de las cuales somos gobernados. Por lo tanto, Foucault nos enseña a tomar en cuenta los principios de sentido común que cualquier 
orden particular de racionalidad de gobierno genera y a pensar en cómo resistirnos u oponernos a ellos: cómo desarrollar principios alternativos, discursos alternativos, pero también cómo reconfigurar la subjetividad que estos modos producen.

Estos dos pensadores son muy poderosos e importantes al momento de pensar en la resistencia política; sin embargo, ninguno de los dos estuvo muy interesado en la democracia, sus instituciones o imaginarios. ¿Por qué preocuparnos por esto? Porque el neoliberalismo produce lo que Foucault llamaría una 'racionalidad de gobierno' que ataca exhaustivamente a las instituciones y a las prácticas democráticas. Esta ha convertido a las democracias en Plutocracias y Plutonomías; pero sobre todo ha desafiado, casi destruyendo, a los imaginarios políticos necesarios para la democracia y las rebeliones democráticas radicales.

Entonces, como usted mencionó, he debido agregar un tercer ángulo a nuestro mapa de coordenadas para teorizar nuestra condición y posibles puntos de resistencia. Dicho esto, considero que la acción política efectiva de izquierda podría, algunas veces, inclinarse hacia una esquina del triángulo y, otras veces, hacia otra. Podría ser protestar contra ataques hacia la democracia, protestar particularmente contra efectos hiper-explotadores o colonizadores del capital - ya sea por parte de bancos, fábricas, el Estado el FMI o la UE-; o podría ser cuestionar la razón de gobierno por la cual las universidades públicas están siendo destruidas y reconfiguradas como un negocio (inhumanamente manejado, en su mayoría) y los estudiantes como endeudados inversionistas de sí mismos.

Ciertamente podríamos intentar tener todos estos elementos presentes en un mismo momento - revelando a las poblaciones en qué clase de sujetos se han convertido, los principios a través de los cuales están viviendo y qué alternativas pueden existir, al tiempo que se revela el funcionamiento 
de las formas actuales de capitalismo y la devastación de instituciones e imaginarios democráticos. Pero se hace lo que se puede - mejor dicho, lo que es más apropiado o efectivo - en cualquier coyuntura política o momento político particular. En diferentes momentos se cuestionan las formas gobernantes de poder de manera distinta y se apunta a diferentes tipos de audiencias. Necesitamos evitar reconvenir a las acciones o actores políticos por esta parcialidad, que es parte del paisaje diverso y las temporalidades complejas de la vida política.

Pregunta 2: Como usted plantea en El Pueblo sin Atributos (2016), el neoliberalismo ha cambiado la naturaleza de la ley, la educación, y la gobernanza estatal. No obstante, con el surgimiento reciente del neoconservadurismo, el papel del Estado constituye seguramente lo más apremiante de esto, y usted ha encontrado correlaciones perturbadoras entre las operaciones del neoliberalismo y el fascismo (2016: 219). ¿Podría explicar a profundidad estas convergencias? ¿Podría la relación entre neoliberalismo y fascismo ayudarnos a comprender el triunfo del Presidente Trump?

Brown: Mucha gente tiende a ver la elección de Trump, el Brexit y el surgimiento de partidos neofascistas o simplemente partidos de extrema derecha - el Frente Nacional en Francia, la Alternativa para Alemania en Alemania - como el fin del Neoliberalismo porque son nacionalistas, se oponen a políticas globales de libre comercio, y se fundan en la exclusión, las barricadas, el proteccionismo.

Creo que sería un error entender a estos a sucesos como opuestos al neoliberalismo, sin embargo, constituyen un cierto tipo de reacción. El Neoliberalismo ha producido las condiciones en las que nos encontramos actualmente, en las que evidenciamos una enorme furia por parte de una población mayoritariamente blanca, que se ha visto destronada de sus 
privilegios económicos y sociales a causa del capitalismo neoliberal. Lo que estamos viendo ahora no son únicamente reacciones hacia los inmigrantes, sino también reacciones hacia estándares de vida decadentes, pérdida de empleos, pérdida de pensiones, el decaimiento de vecindarios, la infraestructura que se desintegra - todas las cosas traídas a nosotros por cuatro décadas de competencia global neoliberal en salarios, impuestos, el estado social, entre otras cosas, que hicieron la vida de la clase trabajadora y la clase media posible. (Especialmente en el Norte Global, en donde nos hemos enfocado durante esta conversación).

Por lo tanto, diría que lo que estamos viviendo hoy en día es en parte una reacción no solo a la devastación económica de la existencia de la clase media y trabajadora, sino también a cierto sentido de supremacía blanca que ha sido atacada por los efectos del neoliberalismo, el cual ha trasladado puestos de trabajo a otras partes del mundo, ha introducido mano de obra barata en países, poblaciones y ciudades que en el pasado solían ser un poco más homogéneas.

Dicho eso, esta reacción ocurre bajo el pretexto de la libertad, moldeada en gran parte por el mismo discurso neoliberal. Los llamados de la derecha a la formación de estados autoritarios y fuertes no deberían distraernos del hecho de que la mayoría de partidos extremos de derecha estén, a su vez, afirmando ser los partidos de la libertad: libertad individual, libertad de expresión y, aún más importante, libertad de declarar al país o a la comunidad como 'propia' de un grupo étnico. Por lo tanto, está operando una noción muy específica de libertad - libertad como propiedad, libertad como lo que Hayek denominó la 'extensión de la esfera personal y privada'-, la cual, por la razón neoliberal, está protegida legítimamente contra la incursión política. Entonces, existe una noción de libertad que está extendiendo las demandas de lo privado hacia la propia figura de la nación. 'Francia para los franceses' y 'America First' podrían ser interpretados como ‘somos nosotros 
quienes tenemos el libre derecho de reclamar en nombre de nuestra propia nación'. Y esa noción de libertad provino directamente del neoliberalismo. Una de las cosas en las que estoy trabajando ahora es intentar localizar las genealogías que han conllevado al neoliberalismo a dar este giro.

Quisiera aclarar una cosa. No estoy sugiriendo que los precursores neoliberales, quienes formularon esta serie de ideas particulares -Hayek, Friedman, los ordoliberales, etc.- hayan tenido en mente los efectos neofascistas o autoritarios que vemos hoy en día. Al contrario: estos fueron pensadores que desarrollaron su pensamiento a la sombra del fascismo y totalitarismo europeo, y que se pensaban a sí mismos como hacedores de un mundo a salvo del fascismo. Sugiero que lo que estamos observando es una suerte de Frankenstein neoliberal: un monstruo -una mutación- que no estuvo en el diseño del neoliberalismo, pero que hoy en día es uno de sus más notables efectos.

Pregunta 3: Uno de los slogans del llamado 'giro a la izquierda' (iniciado por Chávez cuando fue elegido en 1999) fue 'El Retorno del Estado'. Al compararlo con la 'retirada' del Estado en los noventa, este pretendía apuntar al fortalecimiento de las instituciones democráticas para establecer mecanismos de redistribución económica y mayor participación política. Algunos autores (Emir Sader (2008); Atilio Borón (2014)) vieron en este 'Retorno del Estado' un indicador del umbral de un pos-neoliberalismo. No obstante, como usted indica en El Pueblo sin Atributos (2016) el Estado no se debilita con el neoliberalismo, sino que simplemente opera bajo una racionalidad diferente. ¿Qué piensa usted sobre el 'Retorno del Estado' como un señal anti-neoliberal? ¿Qué piensa sobre las aseveraciones de que en el Sur Global nos estamos moviendo hacia una era post-neoliberal?

Brown: Pienso que debemos ser muy cuidadosos al pensar en el Estado. Uno de los errores más grandes de la teoría marxista y neomarxista de 
los sesentas y setentas, que intentó desarrollar una teoría sobre el estado capitalista, fue imaginar que los estados capitalistas, de cualquier era específica, tenían una única forma y que el estado en sí mismo constituía una entidad unificada y coherente. Foucault nos ayuda a desafiar estas ideas con sus genealogías del Estado y su rechazo al Estado Moderno como centro de poder y gobernanza, es decir, con sus nociones de biopolítica y del poder distribuído a través de la sociedad.

En sus cursos del College de France sobre neoliberalismo, desafía aún más el pensamiento marxista al tomar en cuenta el grado en que los estados son reconfigurados por el proyecto político-intelectual del neoliberalismo. Pero unos cuantos de los viejos teóricos del Estado marxistas están llegando también a una comprensión más matizada de los estados capitalistas -pienso en Streeck, Offe, entre otros.

Necesitamos pensar a los Estados en su especificidad. Lo que significa -para referirnos al Norte Global por un momento antes de platicar sobre el Sur- que obviamente existe una diferencia entre los estados keynesianos, o de bienestar social, o social-demócratas y el estado neoliberal. No es que uno sea más grande que el otro, o que uno sea el verdadero estado capitalista y el otro no; todos cumplen funciones diferentes, incluyendo diferentes funciones de legitimación, y les caracteriza, además, diferentes tipos de poder estatal. El neoliberalismo es un proyecto sustancialmente estatal, incluso cuando cuestiona muchos aspectos del estado social-demócrata y el estado liberal. El neoliberalismo redirecciona y reformula el Estado; no reduce sus poderes o importancia.

En cuanto a Chávez, comprendo el efecto retórico al hablar de el 'Retorno del Estado' con fines de redistribución, igualdad y socialización de la economía. Pero es un gesto retórico, porque como bien sabemos por la Venezuela contemporánea, el mismo Estado puede desplegarse 
hacia otras funciones: funciones policiales, funciones militares, funciones administrativas, funciones de corrupción, etc. Por lo tanto, no creo que sea una cuestión de 'sí o no' al Estado. La pregunta para la Izquierda, hoy en día, también en el Sur Global, sería: ¿cómo lidiar de manera política con los esfuerzos para impedir la globalización a nivel local, sin concentrar el poder -todo tipo de poder- en Estados que terminen siendo anti-democráticos en su gestión y funcionamiento?

No es un problema sencillo de resolver. Los Estados siguen siendo un medio importante por el cual las naciones u otros sub-poderes dentro de ellas se adecúan o resisten a las fuerzas de un orden global neoliberalizado. La cuestión de cómo organizar un proyecto de Izquierda -ya sea nacional o sub-nacional- requiere hallar lo que Foucault denominó 'una forma de racionalidad política' que sea democrática, emancipatoria y no solo antineoliberal. Esto es difícil, pero esencial para la Izquierda, ya sea en el Norte como en el Sur.

Pregunta 4: Pareciera que hoy en día, al enfrentarnos a un nuevo contexto político en el 2017, existe la necesidad de diagnosticar nuevamente el estado de la Izquierda. Frente a los nuevos movimientos post-feministas, antifascistas y antirracistas como 'Black Lives Matter', solidaridades internacionales y la elección en algunos lugares de políticos de izquierda; creo que podría ser apremiante regresar a la noción de 'melancolía de la izquierda' como ligada a grandes pérdidas que provocan impotencia política, ira y moralismos. ¿Sigue siendo razonable criticar a las izquierdas como poseedoras de una moral de esclavos 'obstinadamente aferrad[a]s a una cierta ecuación de la verdad, como si accionaran a partir de una voluntad herida' (2014: 23) tal como usted indicó en La Política fuera de la Historia (2014)? Más aún, ¿deberíamos seguir definiendo la relación entre Izquierda y poder como una relación altamente defensiva -como una mentalidad de barrera (2014: 39) - o empiezan a aparecer nuevas formas de acciones políticas afirmativas? 
Brown: Al teorizar sobre los apegos heridos y la melancolía de la Izquierda -un tipo de entrega a un estatus de inocencia, pureza, bondad, verdad y belleza, con todo el mal concentrado al otro lado- me interesaba en ciertas tendencias históricas específicas de la Izquierda, que la debilitaron y limitaron sus poderes y visión. Pero estas teorías no pretendían ser definiciones totalizantes de la Izquierda, descripciones que condenen o expliquen todo sobre ella. Aquellas tendencias podrían no ser nuestro más grande problema hoy en día, pero aún existen y debemos estar alertas. Aún así, creo que ahora existe algo más importante ante nosotros.

Ha sido muy difícil para la Izquierda, a raíz de los fallidos experimentos comunistas y socialistas del siglo veinte, responder a la pregunta sobre ¿cuál es nuestra visión de una economía política emancipatoria, modestamente igualitaria y sostenible; y de la política democrática, en un mundo conectado, complejo y diverso? ¿Es local, nacional, global?, ¿Cómo concibe la diferencia? ¿Cómo lidia con la variedad de poderes, ajenos a la clase, que ni Marx, ni el comunismo atendieron de manera suficiente - raza, género, sexualidad, etc.-, pero también con los poderes de la vida política y psíquica que no desaparecerán con el fin de la propiedad privada? En resumen: ¿qué clase de visión, verdaderamente convincente, poseemos de acuerdos humanos, políticos, sociales y económicos que velen por nosotros en este mundo de pesadilla? Ésta es una tarea difícil, pero no puede ser eludida.

Esto se relaciona con el segundo desafío que consiste en ¿cómo involucrarse con la resistencia u oposición - ya sea a la devastación del planeta, regímenes neofascistas o violaciones a los derechos humanos - y al mismo tiempo ofrecer una visión que contemple acuerdos alternativos? ¿Cómo tener una política que trascienda la postura de 'esta violencia es terrible', 'este régimen es espantoso', 'esto nos oprime' o 'esta especie o topografía está siendo destruída', y que en lugar, luche contra estos males, ofreciendo, al mismo tiempo, una visión de transformación profunda? ¿Un 
orden en el que estas pesadillas no sean posibles? ¿Cómo ir más allá de la crítica y la resistencia?

Hoy en día existen muchas formas de acción política que se esfuerzan por ir en esta dirección. Hay toda clase de experimentos con la 'política prefigurativa' y esfuerzos de oposición que son coalicionales, multidimensionales, abiertos y plurales - esfuerzos que procuran ser transformativos mientras resisten. Al mismo tiempo, algunos de los problemas a los que he dedicado mi vida intentando advertir en la política de Izquierda son cosas a las que aún necesitamos poner atención. La melancolía de la Izquierda sigue siendo un peligro, al igual que los proyectos de Izquierda que no asumen los retos de un mundo globalizado, los retos de la diferencia y los retos del poder político - no solo económico y social. Las Izquierdas aún son proclives a creer en "somos justos, somos la verdad, somos los inocentes" - lo que es inútil al momento de llegar a acuerdos dentro de la Izquierda e irrelevante para aquellos que se encuentran fuera de ella. A la izquierda aún le hace falta una alternativa al capitalismo global, que sea inteligente, inteligible y ampliamente compartida.

Por lo tanto, sí. Concuerdo con usted en que varios de los proyectos de Izquierda, formulados por la juventud, son hoy en día excesivamente emocionantes y cargados del tipo de energía necesaria para establecer vínculos y coaliciones, así como políticas prefigurativas. Sin embargo, todavía nos enfrentamos al peligro de un capitalismo integrado globalmente y dominado por las finanzas, que literalmente terminará con la vida si no lo reemplazamos por otra cosa. ¿Cómo reforzar proyectos existentes de la Izquierda, combatir la oscuridad y diseñar una alternativa al orden actual de las cosas? ¿Cómo luchar local y globalmente? ¿Cómo tener coraje, humildad, ironía, apertura y perseverancia? Estos son nuestros retos. 
Pregunta 5: En el epílogo de El Pueblo sin Atributos (2016), usted propone la idea de una 'democracia desnuda' que no puede formar parte de ninguna gubernamentalidad ya que "no presenta una narrativa continua o consistente de por qué el pueblo debe gobernar, solo la negativa de que no debemos ser gobernados por otros' (2016: 203) ¿Podría profundizar un poco más sobre esta idea de la 'democracia desnuda'? ¿Podría existir algo así como una parte positiva y productiva de la democracia en el sentido foucaultiano o, en otras palabras, una 'racionalidad democrática gubernamental'?

Brown: Por 'democracia desnuda' me refería simplemente al significado más ínfimo que se puede atribuir a la noción de democracia, y realmente me estaba remitiendo a sus dimensiones etimológicas -democracia, demoskratia, el gobierno del pueblo-, el que se diferencia de 'el gobierno de uno solo', 'el gobierno de unos pocos', 'el gobierno de las corporaciones', 'el gobierno de la tecnocracia', 'el gobierno de los algoritmos', 'el gobierno del capital'. El gobierno del pueblo es la democracia desnuda, en el sentido de que es el significado más puro que la democracia puede tener.

Después de que se ha establecido que 'el pueblo debe gobernar', todo está por pensarse y por hacerse. ¿Cómo gobierna el pueblo? ¿Gobierna a través de la elección de representantes? Marx y otros nos recuerdan que eso no es precisamente 'el gobierno del pueblo', sino entregar a otra persona la capacidad propia de gobernar. ¿Gobernamos directamente? ¿Cómo? ¿Aún gobierna uno mismo si se es parte de una minoría que es gobernada por la mayoría? ¿Gobernamos legislando o gobernamos por mandato? ¿Nos gobernamos a nosotros mismos poseyendo y controlando colectivamente los medios de producción, como lo habría hecho Marx? ¿Es así como el gobierno del pueblo funciona realmente? O, como algunos teóricos políticos sugieren, ¿funciona al atribuirnos a nosotros mismos los principios básicos, las normas básicas, por las cuales debemos vivir? ¿Está, como Rousseau 
sugirió, ese proyecto político disociado de la propiedad y manejo colectivo de nuestros medios de subsistencia?

Lo que intentaba sugerir es que estar comprometido con la democracia no significa estar comprometido con una forma u otra -burguesa, radical, directa, liberal, constitucional, social. En otras palabras, la democracia es, en sí misma, una noción y práctica cuestionable, debatible e históricamente toma forma y contenido en diferentes contextos culturales, económicopolíticos, religiosos. Por lo tanto, la democracia desnuda sencillamente expresa la noción de que no hemos renunciado a la idea de gobernarnos a nosotros mismos. El neoliberalismo ha renunciado a ella al decir: 'es mucho mejor ser gobernado por el mercado, que por el pueblo'. La Unión Europea ha renunciado a ella, al decir 'es mucho mejor ser gobernado por la tecnocracia, algoritmos y expertos'. Y, por supuesto, los nuevos regímenes autoritarios están renunciando a ella.

Más que solo luchar por la igualdad o liberación de la opresión, pienso que la Izquierda debe luchar por un orden en el que la gente verdaderamente se gobierne a sí misma. Esa es la única esperanza que tenemos de mantener vivo al planeta y proteger la diversidad de vida, incluyendo la variedad de vida humana que habita en él. Por lo tanto, mi interés por la democracia, más allá de alejarse de la política radical de la Izquierda, aumenta las exigencias sobre ella: igualdad política y social, sí; producción sostenible para las personas y especies planetarias, sí; abolición de la explotación e instrumentalización, sí; pero también autogobierno colectivo.

\section{Referencias}

Borón, A. (2014). Twenty-first Century Socialism: is there life after Neoliberalism? Nova Scotia: Fernwood Publishing.

Brown, W. (2014). La Política fuera de la Historia. Madrid: Enclave de libros. 
Brown, W. (2016). El pueblo sin atributos. Barcelona: Ediciones Malpaso.

Sader, E. (2008). Posneoliberalismo en América Latina. Buenos Aires: CLACSO. 
